\title{
Persisting myocardial sympathetic dysfunction in takotsubo cardiomyopathy
}

\author{
Hein J. Verberne, MD, PhD, ${ }^{\text {a }}$ Dirk J. van der Heijden, MD, ${ }^{b}$ Berthe L. F. \\ van Eck-Smit, $M D, P h D,{ }^{a}$ and $G$. Aernout Somsen, $M D, P^{c}$
}

A 73-year-old woman without a cardiovascular history was admitted with chest discomfort, dizziness, and nausea after an emotional meeting with the staff of a nursing home. She experienced the same complaints some years before when her father died.

On admission the patient was in cardiogenic shock. Auscultation of the heart revealed a grade 3/6 systolic murmur radiating to the left axilla. The electrocardiography (ECG) showed an acute anterior wall infarction (Figure 1). Acute coronary angiography was performed but no significant coronary artery disease was found. Left ventricular (LV) angiography showed severe mitral regurgitation and apical ballooning (Figure 2). An intraventricular gradient of $100 \mathrm{mmHg}$ was measured. Echocardiography showed apical akinesia and basal hyperkinesia resulting in severe mitral regurgitation due to systolic anterior movement of the anterior mitral valve leaflet. Troponin $\mathrm{T}(1.73 \mathrm{ng} / \mathrm{L})$ and $\mathrm{CK}-\mathrm{MB}$ $(22 \mu \mathrm{g} / \mathrm{L})$ were slightly increased. Based on these findings, the diagnosis of a takotsubo cardiomyopathy (TC) was made. Shortly after treatment with intravenous inotropics, and ACE inhibition the patient became hemodynamically stable and metoprolol was added.

Cardiac MRI did not show late contrast enhancement which excludes myocardial fibrosis and myocardial infarction as the cause of the hemodynamic instability. Myocardial ${ }^{123}$ I-metaiodobenzylguanidine ( ${ }^{123} \mathrm{I}-\mathrm{MIBG}$, a radiolabelled noradrenalin analog) scintigraphy, performed 4 days after admission, showed diffuse reduced myocardial uptake and increased washout of ${ }^{123} \mathrm{I}-\mathrm{MIBG}$ which reflects impaired sympathetic neuronal function

From Department of Nuclear Medicine, ${ }^{\mathrm{a}}$ Academic Medical Center, University of Amsterdam, Amsterdam 1100 DE, The Netherlands and Department of Cardiology, ${ }^{\mathrm{b}}$ Rijnland Ziekenhuis, Leiderdorp, The Netherlands and Department of Cardiology, ${ }^{c}$ Onze Lieve Vrouwe Gasthuis, Amsterdam, The Netherlands.

Reprint requests: Hein J. Verberne, MD, PhD, Department of Nuclear Medicine, Academic Medical Center, University of Amsterdam, P.O. Box 22700, Amsterdam 1100 DE, The Netherlands; h.j.verberne@ amc.uva.nl.

J Nucl Cardiol 2009;16:321-4.

$1071-3581 / \$ 34.00$

Copyright $(\subset) 2008$ The Author(s). This article is published with open access at Springerlink.com.

doi:10.1007/s12350-008-9017-1 and increased sympathetic activity, respectively (Figure $3 \mathrm{~A})$. Cardiac ultrasound was repeated at 3 and 7 months and showed no mitral regurgitation and a normalized LV function. However, cardiac sympathetic neuronal function and activity remained abnormal as was shown by ${ }^{123}$ I-MIBG scintigraphy at 3 and 7 months (Figure 3B and $\mathrm{C}$, respectively).

The diagnosis of a stress-induced cardiomyopathy, apical ballooning syndrome or TC was based on the presence of the typical symptoms and signs of an anterior wall infarction after a highly stressful moment (a lifetime crisis), combined with normal coronary angiography, LV apical ballooning, no signs of late contrast enhancement on MRI scanning, and rapid recovery of LV function. ${ }^{1}$

The name Takotsubo is related to the morphology of the left ventricle, which shows resemblance to a Japanese round-bottomed narrow-necked fishing pot used for trapping octopus. Postmenopausal women seem to be most at risk for developing this syndrome, especially after an episode of acute emotional stress. In a systematic review, women accounted for $82-100 \%$ of patients with an average age of 62-75 years, although cases have been described in individuals aged 10-91 years. ${ }^{2}$ Formal diagnostic criteria have yet to be established. Bybee et al have suggested diagnostic criteria for TC, requiring the following: (1) transient LV wall motion abnormalities involving the apical and/or midventricular myocardial segments with wall motion abnormalities extending beyond a single epicardial coronary distribution; (2) absence of obstructive epicardial CAD or angiographic evidence of acute plaque rupture that could be responsible for the observed wall motion abnormality; and (3) new ECG abnormalities such as transient ST-segment elevation and/or diffuse $\mathrm{T}$-wave inversions or Troponin $\mathrm{T}$ elevation. ${ }^{2-4}$

Although the exact pathophysiology of $\mathrm{TC}$ is unknown, it has been suggested that catecholaminemediated cardiac toxicity is related to the pathophysiological basis of TC. In these patients, increased myocardial sympathetic activity is caused by increased presynaptic release and reduced re-uptake of noradrenalin. This leads to down regulation and desensitization of the postsynaptic cardiac $\beta$-adrenoreceptors, leading to 


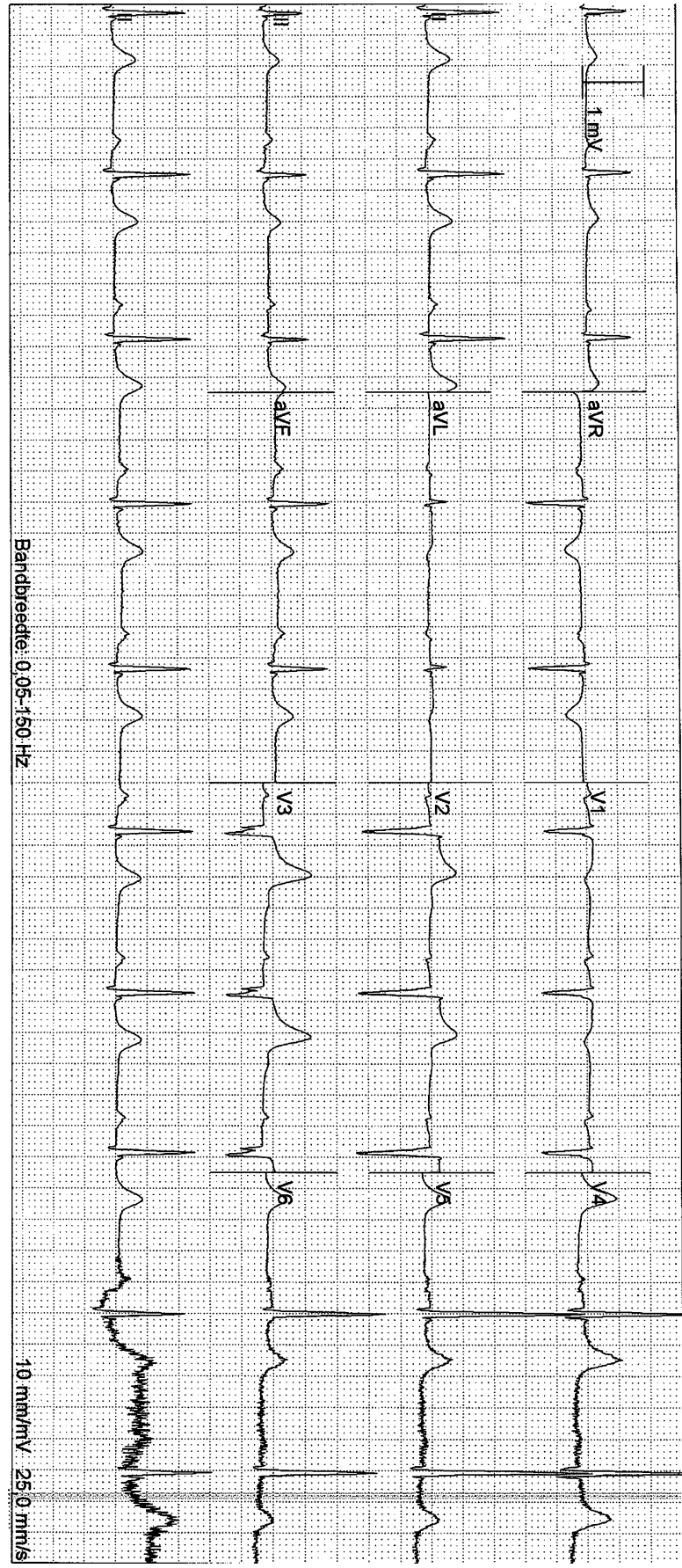

Figure 1. ECG at admission suggestive for an acute anterior wall infarction: sinus-rhythm with 58 beats per minute, 1 st degree AV block, ST segment elevation in leads V1-V4, and pathological Q waves in V2 and V3.

a further decline of the LV function. ${ }^{5}$ The changes in the presynaptic myocardial sympathetic activity can be assessed with the radio-labeled noradrenalin analog ${ }^{123}{ }^{2}$-MIBG. ${ }^{6}$ However, it has been shown that some $\beta$-adrenoreceptor-blockers may influence myocardial ${ }^{123}$ I-MIBG uptake. This has also been suggested for

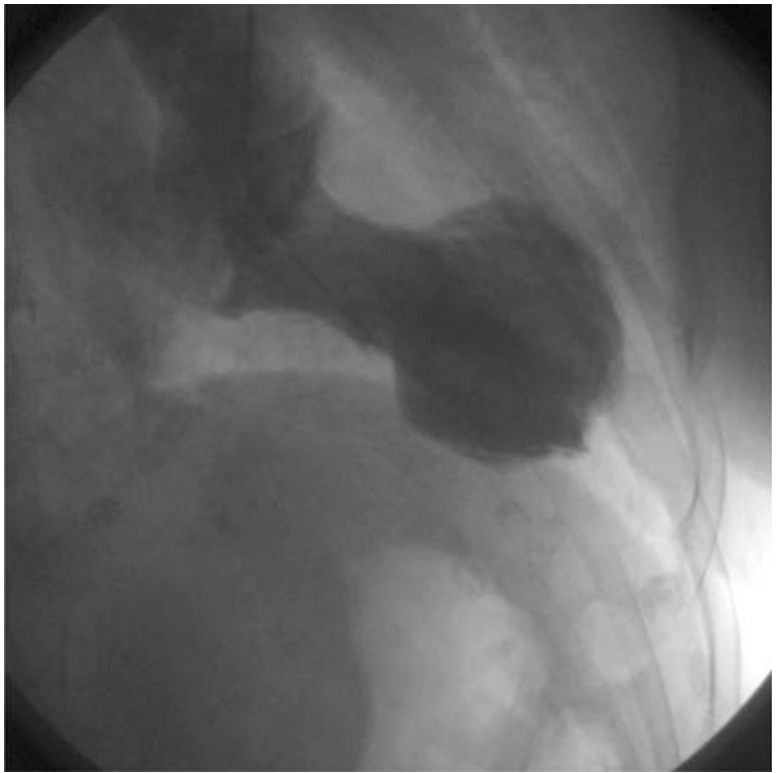

Figure 2. Left ventricular (LV) angiography showing severe mitral regurgitation and apical ballooning.

ACE-inhibitors. This may explain in part the initial scintigraphic findings. However, in the case report of Moreo et al ${ }^{123}$ I-MIBG myocardial uptake increased, after a 2-month treatment with carvedilol. ${ }^{6}$ Moreover, in patients with heart failure $\beta$-adrenoreceptor-blockers and ACE inhibitors are associated with an increase in ${ }^{123}$ I-MIBG uptake and reduced washout. ${ }^{7,8}$ In our patient ACE inhibition was discontinued after the acute phase and the $\beta$-adrenoreceptor-blocker was continued. Another possible confounding factor of persisting abnormal ${ }^{123}$ I-MIBG scintigraphic findings is denervation due to a previous myocardial infarction. However, MRI showed no signs of a previous myocardial infarction. Taken together it is likely that the scintigraphic images, at presentation and during follow-up, reflect true persisting increased myocardial sympathetic activity.

Another possible pathophysiological mechanism for the development of TC might be related to stress-induced coronary epicardial spasm or endothelial dysfunction resulting in myocardial stunning. In a recent study, Sato et al evaluated coronary artery endothelial dysfunction in 35 patients with TC. ${ }^{9}$ In $54 \%$ of patients with TC, diffuse coronary vasoconstriction occurred after intracoronary acetylcholine provocation. In the acute phase, myocardial perfusion and myocardial fatty acid metabolism scintigraphy ( ${ }^{123} \mathrm{I}$-BMIPP) were impaired. During follow-up myocardial perfusion and myocardial fatty acid metabolism improved to normal in association with improvement of LV function. Myocardial stunning due to stressinduced coronary epicardial spasm or endothelial dysfunction might therefore be a likely explanation for TC. 


\section{A}

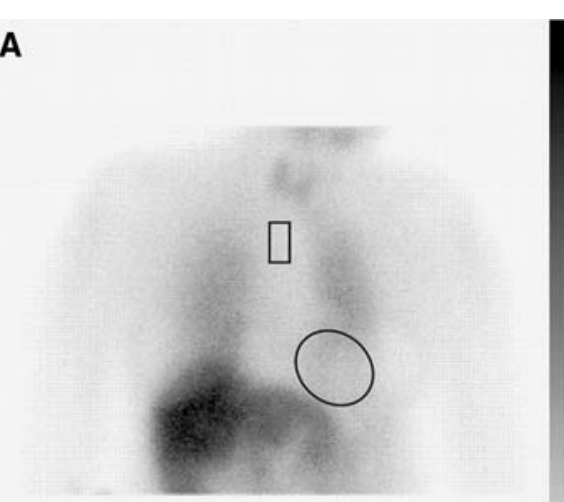

15 min p.i.

B

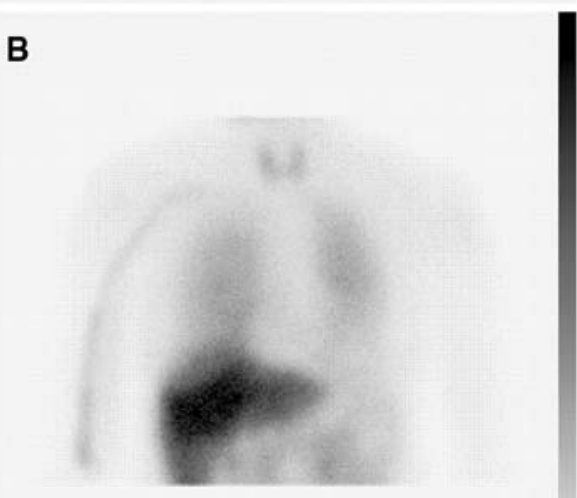

$15 \min$ p.i.

C

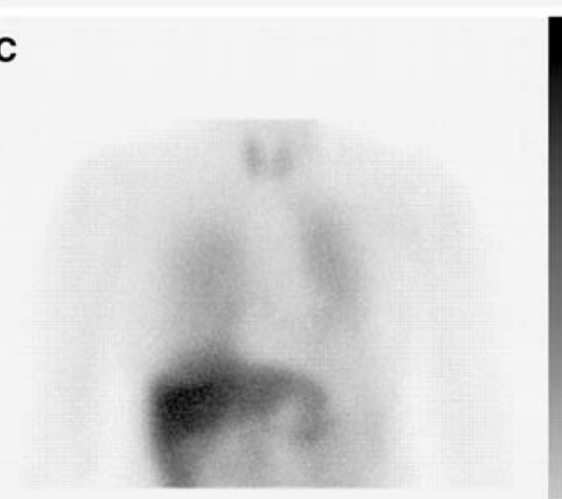

15 min p.i.
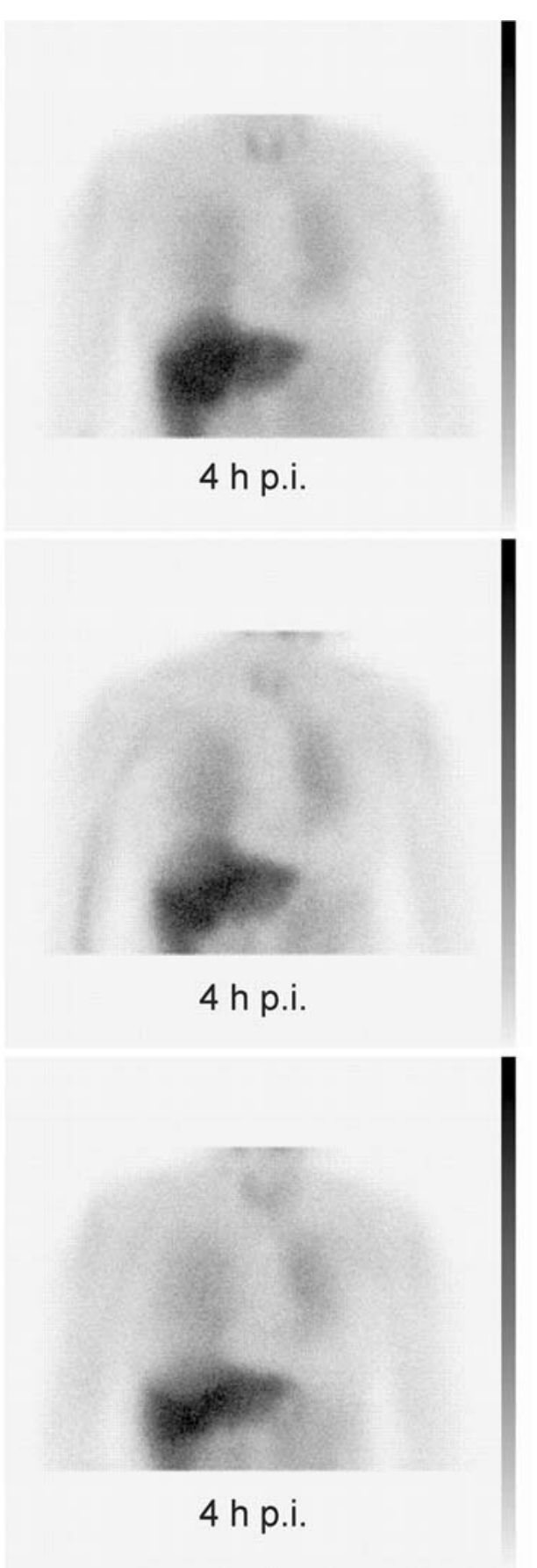

Figure 3. ${ }^{123}$ I-MIBG scintigraphy: images on the left were made 15 min postinjection (p.i.) of ${ }^{123}$ I-MIBG (early) and the images on the right were made $4 \mathrm{~h}$ p.i. (late). Upper left panel shows the regions of interest over the myocardium and mediastinum for the calculation of the semiquantitative parameters of ${ }^{123}$ I-MIBG myocardial uptake and washout. ${ }^{123}$ I-MIBG images 4 days after hospital admission, show severely reduced myocardial uptake (A). Semiquantitative analysis of the myocardial uptake confirmed the visual interpretation (early heart/mediastinal $(\mathrm{H} / \mathrm{M})$ ratio: 1.54 , late H/M: 1.26 and myocardial washout of ${ }^{123}$ I-MIBG: $\left.18 \%\right)$. Three (B) and seven months $(\mathbf{C})$ after hospital admission ${ }^{123}$ I-MIBG myocardial uptake and washout remained abnormal. The semiquantitative parameters remained abnormal after 3 months (early H/M: 1.78 , late H/M: 1.33, and myocardial washout of ${ }^{123} \mathrm{I}-\mathrm{MIBG}: 25 \%$ ) and after 7 months (early H/M: 1.66 , late H/M: 1.13 , and myocardial washout of ${ }^{123} \mathrm{I}-\mathrm{MIBG}$ : $32 \%$ ). Due to the diffuse reduced myocardial ${ }^{123} \mathrm{I}-\mathrm{MIBG}$ uptake SPECT images could not reliably be reconstructed. 
Assessment of myocardial perfusion with SPECT and PET tracers and assessment of glucose metabolism with ${ }^{18}$ F-FDG have been used to evaluate TC patients. ${ }^{10-15}$ Typically in the early/acute phase of TC myocardial perfusion can be (regionally, i.e., apex) disturbed and shows an impaired (regional, i.e., apex) coronary flow reserve (CFR) and a more pronounced impairment of (regional, i.e., apex) myocardial glucose metabolism. In general, the regional reduction of perfusion and impairment of glucose metabolism have the tendency to resolve completely 3 months after the early/ acute phase.

In our patient, myocardial sympathetic activity was increased in the early phase of TC. Although LV function was completely normalized, increased myocardial sympathetic activity persisted. Normalization of myocardial ${ }^{123}$ I-MIBG uptake has been described in several case reports. ${ }^{6,16}$ This is the first report showing persisting sympathetic dysfunction in a patient with TC after complete normalization of the $\mathrm{LV}$ function and no signs of late enhancement on MRI. The recurrence of TC is rare and is estimated at $2.9 \%$ per year and the overall cardiovascular survival is not different from age- and gender-matched controls. ${ }^{17}$ Echocardiographic follow-up of TC patients has never been performed in a consistent way. This may implicate that the recurrence rate of TC is underestimated. In the present case, the patient experienced the same symptoms after an emotional event several years earlier which may have been an earlier episode of TC.

Predictors of TC recurrence are not known. As TC is associated with a hyperadrenergic state, the persisting increased myocardial sympathetic activity may have prognostic implications. ${ }^{18}$ Therefore, myocardial ${ }^{123}$ I-MIBG scintigraphy may identify patients at risk for the recurrence of TC. These findings may warrant extensive pharmacological therapy and follow-up in TC patients. Theoretically, recurrence rates may be lower in those who are maintained on adrenergic blockade assuming that catecholamines play a central role in the pathogenesis of the syndrome.

\section{Open Access}

This article is distributed under the terms of the Creative Commons Attribution Noncommercial License which permits any noncommercial use, distribution, and reproduction in any medium, provided the original author(s) and source are credited.

\section{References}

1. Sharkey SW, Lesser JR, Zenovich AG, Maron MS, Lindberg J, Longe TF, et al. Acute and reversible cardiomyopathy provoked by stress in women from the United States. Circulation 2005; 111:472-9.
2. Bybee KA, Kara T, Prasad A, Lerman A, Barsness GW, Wright RS, et al. Systematic review: Transient left ventricular apical ballooning: A syndrome that mimics ST-segment elevation myocardial infarction. Ann Intern Med 2004;141:858-65.

3. Bybee KA, Prasad A. Stress-related cardiomyopathy syndromes. Circulation 2008;118:397-409.

4. Prasad A. Apical ballooning syndrome: An important differential diagnosis of acute myocardial infarction. Circulation 2007;115: e56-9.

5. Lefkowitz RJ, Caron MG, Stiles GL. Mechanisms of membranereceptor regulation. Biochemical, physiological, and clinical insights derived from studies of the adrenergic receptors. N Engl J Med. 1984;310:1570-9.

6. Moreo A, De Chiara B, Possa M, Sara R, Bossi I, Orrego PS, et al. Functional derangement and cardiac innervation in the apical ballooning syndrome: a ${ }^{123}$ I-meta-iodobenzylguanidine scintigraphic and dobutamine stress echocardiographic study. J Cardiovasc Med 2007;8:205-9.

7. de Milliano PA, de Groot AC, Tijssen JG, van Eck Smit BL, van Zwieten PA, Lie KI. Beneficial effects of metoprolol on myocardial sympathetic function: Evidence from a randomized, placebo-controlled study in patients with congestive heart failure. Am Heart J 2002;144:E3.

8. Somsen GA, van Vlies B, de Milliano PA, Borm JJ, van Royen EA, Endert E, et al. Increased myocardial $\left[{ }^{123} \mathrm{I}\right]$-metaiodobenzylguanidine uptake after enalapril treatment in patients with chronic heart failure. Heart 1996;76:218-22.

9. Sato A, Aonuma K, Nozato T, Sekiguchi Y, Okazaki O, Kubota K, et al. Stunned myocardium in transient left ventricular apical ballooning: A serial study of dual I-123 BMIPP and Tl-201 SPECT. J Nucl Cardiol 2008;15:671-9.

10. Feola M, Chauvie S, Rosso GL, Biggi A, Ribichini F, Bobbio M. Reversible impairment of coronary flow reserve in takotsubo cardiomyopathy: A myocardial PET study. J Nucl Cardiol 2008; 15(6):811-17

11. Cimarelli S, Imperiale A, Ben-Sellem D, Rischner J, Detour J, Morel $\mathrm{O}$, et al. Nuclear medicine imaging of takotsubo cardiomyopathy: Typical form and midventricular ballooning syndrome. J Nucl Cardiol 2008;15:137-41.

12. Alexanderson E, Cruz P, Talayero JA, Damas F, Zeron J, Meave A. Transient perfusion and motion abnormalities in takotsubo cardiomyopathy. J Nucl Cardiol 2007;14:129-33.

13. Bybee KA, Murphy J, Prasad A, Wright RS, Lerman A, Rihal CS, et al. Acute impairment of regional myocardial glucose uptake in the apical ballooning (takotsubo) syndrome. J Nucl Cardiol 2006;13:244-50.

14. Scholte AJ, Bax JJ, Stokkel MP, Plokker T, Kaandorp TA, Lamb $\mathrm{HJ}$, et al. Multimodality imaging to diagnose takotsubo cardiomyopathy. J Nucl Cardiol 2006;13:123-6.

15. Obunai K, Misra D, Van Tosh A, Bergmann SR. Metabolic evidence of myocardial stunning in takotsubo cardiomyopathy: A positron emission tomography study. J Nucl Cardiol 2005;12:742-4.

16. Ito $K$, Sugihara $H$, Kinoshita N, Azuma A, Matsubara $H$. Assessment of Takotsubo cardiomyopathy (transient left ventricular apical ballooning) using ${ }^{99 \mathrm{~m}} \mathrm{Tc}$-tetrofosmin, ${ }^{123} \mathrm{I}$-BMIPP, ${ }^{123} \mathrm{I}-\mathrm{MIBG}$ and ${ }^{99 \mathrm{~m}} \mathrm{Tc}-\mathrm{PYP}$ myocardial SPECT. Ann Nucl Med 2005;19:435-45.

17. Elesber AA, Prasad A, Lennon RJ, Wright RS, Lerman A, Rihal CS. Four-year recurrence rate and prognosis of the apical ballooning syndrome. J Am Coll Cardiol 2007;50:448-52.

18. Wittstein IS, Thiemann DR, Lima JAC, Baughman KL, Schulman SP, Gerstenblith G, et al. Neurohumoral features of myocardial stunning due to sudden emotional stress. N Engl J Med 2005;352: $539-48$. 